\title{
EFEITO DO USO DE ÓRTESE DE PUNHO NA ATIVAÇÃO DA MUSCULATURA FLEXORA E EXTENSORA DO PUNHO
}

\author{
EFFECT OF THE USE OF WRIST ORTHOSIS ON FOREARM MUSCLE ACTIVATION
}

Adriana Maria Valladão Novais Van Petten', Antônio Ferreira Ávila²

\section{RESUMO}

Objetivo: Analisar o efeito do uso de órtese de imobilização do punho, confeccionada com diferentes materiais, na ativação da musculatura flexora e extensora do antebraço durante a realização de tarefas específicas. Métodos: Vinte e seis adultos, com média de idade de 26,2 anos, foram submetidos aos Testes Funcional da Mão de Jebsen-Taylor e de Força de Preensão (dinamômetro Jamar $\left.{ }^{\circledR}\right)$ em três condições: com a mão livre, com o uso de órtese de compósito e com a órtese de termomoldável. Os testes foram realizados apenas com a mão dominante. Durante a realização dos testes, eletrodos de superfície foram afixados nos grupos musculares flexores e extensores do antebraço para registro da atividade elétrica muscular. Os resultados obtidos nas três condições foram comparados e analisados utilizando o teste estatístico de Wilcoxon. Resultados: Foram encontradas diferenças significativas quando comparadas a ativação muscular na condição livre e com o uso de qualquer das órteses. Não foram encontradas diferenças significativas quando comparada a ativação muscular com o uso dos dois tipos de órtese. Observou-se redução da ativação dos músculos extensores do antebraço durante a realização de todas as tarefas e aumento da ativação dos músculos flexores com o uso das órteses. Conclusão: Esse é um resultado importante para a definição da indicação, ou não, do uso de órteses no processo de reabilitação de várias desordens - entre outras, a tendinite de flexores e extensores do punho e dos dedos -, bem como para a previsão do tempo de uso desses dispositivos.

Descritores - Aparelhos ortopédicos; Punho; Eletromiografia

\section{ABSTRACT}

Objective: to investigate the effect of wrist immobilization orthoses, made from different materials, on activation of the flexor and extensor musculature of the forearm while performing specific tasks. Methods: Twenty-six adults, with an average age of 26.2 years, performed the Jebsen-Taylor functional hand test and the Grip Strength test (James ${ }^{\circledR}$ dynamometer) under three conditions: free hand, wearing a composite orthosis, and wearing a thermoplastic orthosis. The tests were carried out using the dominant hand only. During the tests, surface electrodes were placed on the flexor and extensor muscles of the forearm to record the electrical muscle activity. The results obtained in the three conditions were compared, and the results analyzed using the statistical Wilcoxon Test. Results: Significant differences were found in muscle activation when comparing the free hand with the use of any of the orthoses. In the comparison of data for the two different orthoses, no significant differences were found. A decrease in activity of the extensor muscles of the forearm was observed during all the tasks, as well as an increase in activation of the flexor muscles with the use of the orthoses. Conclusion: These results are important for the prescription of an orthosis during the rehabilitation process of a wide range of pathologies, such as tendinitis of the flexors and extensors of the first and fingers, as well as for forecasting the time of use of these devices.

Keywords - Orthopedic devices; Wrist; Electromyography

\section{INTRODUÇÃO}

A tecnologia de assistência tem sido usada como uma alternativa de intervenção no sentido de aumentar a habilidade funcional de pacientes em atividades de autocuidado, trabalho e lazer ${ }^{(1)}$, bem como suporte para a vida e a participação na comunidade ${ }^{(2)}$. Entre os diversos tipos de tecnologia de assistência, a órtese destaca-se como um recurso importante no processo de reabilitação.
Em função da especificidade de cada cliente, esse dispositivo pode se caracterizar por objetivos diversos - proteger a cicatrização de estruturas; manter ou promover a amplitude de movimento de determinada articulação; substituir ou aumentar uma função; prevenir ou corrigir deformidades; oferecer repouso articular; reduzir a dor; servir como base para acessório de autoajuda, entre outros ${ }^{(3,4)}$. Assim, o modelo e a fabricação das ór-

1 - Doutora em Engenharia Mecânica - UFMG, Departamento de Terapia Ocupacional, Universidade Federal de Minas Gerais, Belo Horizonte, MG - Brasil.

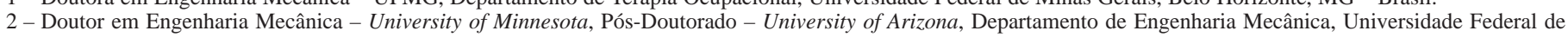
Minas Gerais, Belo Horizonte - Brasil.

Correspondência: Rua Ministro Hermenegildo de Barros, 765 - Itapoã - 31.710-230 - Belo Horizonte, MG - Brasil. E-mail: avaladao@ufmg.br. 
teses utilizadas em diferentes processos de reabilitação podem variar de simples a complexos ${ }^{(5)}$, e o material empregado na sua confecção deve atender às exigências da complexidade de cada um desses dispositivos.

Muitos têm sido os questionamentos sobre a influência desses dispositivos no uso funcional da mão, em especial quando se trata de órteses de imobilização do punho. Esse tipo de órtese, geralmente indicada no tratamento de pessoas que apresentam diversas condições, objetiva proteger a cicatrização de tecidos ou estruturas ${ }^{(6)}$ e permitir a função manual necessária à realização de atividades do cotidiano ${ }^{(7,8)}$. Uma questão frequentemente discutida é a influência do uso de órtese no grau de ativação dos músculos extensores e flexores do punho durante a realização de tarefas do cotidiano. Considerase o punho uma articulação estratégica na cadeia cinética que regula a eficácia dos movimentos digitais da função da mão ${ }^{(9)}$. É a posição do punho que mantém a unidade musculotendínea extrínseca em tensão crítica e é a partir da definição do arco de movimento do punho que a mão pode demonstrar seu conjunto de movimentos funcionais ${ }^{(9)}$. Na execução dos movimentos funcionais da mão, os músculos do punho são responsáveis por proporcionar estabilidade a essa articulação, por aumentar a força de preensão e, ainda, por posicionar os dedos ${ }^{(10)}$.

Para se manter a estabilidade do punho, fazem-se necessárias tanto a coativação quanto a ativação individual dos flexores e extensores do punho ${ }^{(11)}$. Os extensores do punho têm, especificamente, o duplo papel de, ao mesmo tempo, inibir e estabilizar forças durante o movimento de preensão ${ }^{(12,13)}$. No caso específico das tendinites de extensores do punho ou epicondilite lateral, a premissa básica para a indicação de órteses de imobilização do punho em extensão é a necessidade de, durante as atividades funcionais, proporcionar repouso aos músculos extensores do punho. Nesse caso, a hipótese é a de que a imobilização do punho em extensão, mediante uso de órtese, irá diminuir a atividade dos músculos extensores durante a realização das tarefas cotidianas. Acredita-se que essa redução irá ocorrer porque o uso desse dispositivo substitui a ação primária dos extensores - a de extensão do punho - e mantém a musculatura encurtada. O objetivo deste estudo foi verificar se o uso de órtese de imobilização do punho em extensão, confeccionada com diferentes materiais, permite a redução da ativação dos músculos extensores do punho durante a realização de tarefas cotidianas.

\section{MÉTODOS}

\section{Amostra}

Foi realizado um estudo quase experimental, do qual participaram 26 adultos (19 do gênero feminino e sete do masculino), voluntários, sem alteração dos membros superiores, com idade média de 26,2 anos. Os critérios de inclusão foram: idade entre 20 anos e 50 anos, ausência de distúrbios neuromusculoesqueléticos nos membros superiores, ausência de dor na região do punho nas últimas duas semanas.

O cálculo do tamanho da amostra utilizado neste estudo baseou-se em efeito semelhante documentado, na literatura, por Johansson et $a^{(13)}$. Com base nos resultados desse estudo e considerando-se uma análise não direcional, com nível de significância $\alpha=0,05$, para um poder estatístico (power) de 0,99 e um efeito esperado de magnitude $d=1,97$, a amostra necessária determinada para o presente estudo foi, conforme tabela também contida na literatura ${ }^{(14)}$, de $\mathrm{n}=20$, valor a que se acresceram 30\% como margem de segurança.

Todos os participantes, antes de sua inclusão no grupo a ser estudado, foram devidamente informados sobre os objetivos pretendidos e os procedimentos a serem praticados e, em seguida, solicitados a assinar o Termo de Consentimento Livre e Esclarecido, aprovado pelo Comitê de Ética em Pesquisa da Universidade Federal de Minas Gerais (Parecer ETIC n0 017/05).

\section{PROCEDIMENTOS}

Cada participante foi submetido a duas avaliações - a primeira, para entrevista inicial e confecção das órteses sob medida; a segunda, para avaliação da influência do uso das órteses na ativação da musculatura flexora e extensora do punho. Cada avaliação foi previamente agendada de acordo com a disponibilidade do voluntário. No momento da entrevista inicial, foram confeccionadas, sob medida, duas órteses para cada um dos participantes - uma, com o material compósito tipo sanduíche, desenvolvido pelos autores em estudo anterior ${ }^{(15)}$; outra com material termomoldável disponível no mercado (Ezeform ${ }^{\circledR}$ - padrão-ouro). O Ezeform ${ }^{\circledR}$ foi escolhido como padrão-ouro por fazer parte do principal grupo de material utilizado na prática clínica para a confecção de órteses, por ser um dos materiais com maior rigidez e, portanto, passível de ser utilizado para a confecção de diferentes dispositivos ortóticos ${ }^{(16)}$.

O dispositivo testado foi uma órtese de imobilização do punho em extensão, como mostra a Figura 1. A escolha desse tipo de órtese deveu-se ao fato de ela ser frequentemente prescrita no tratamento de diversas sequelas de desordens do sistema neuromusculoesquelético - entre outras, mão hemiparética ${ }^{(17)}$, síndrome do túnel do carpo $^{(18,19)}$, quadriplegia ${ }^{(20)}$ e epicondilite lateral ${ }^{(21,22)}$. 


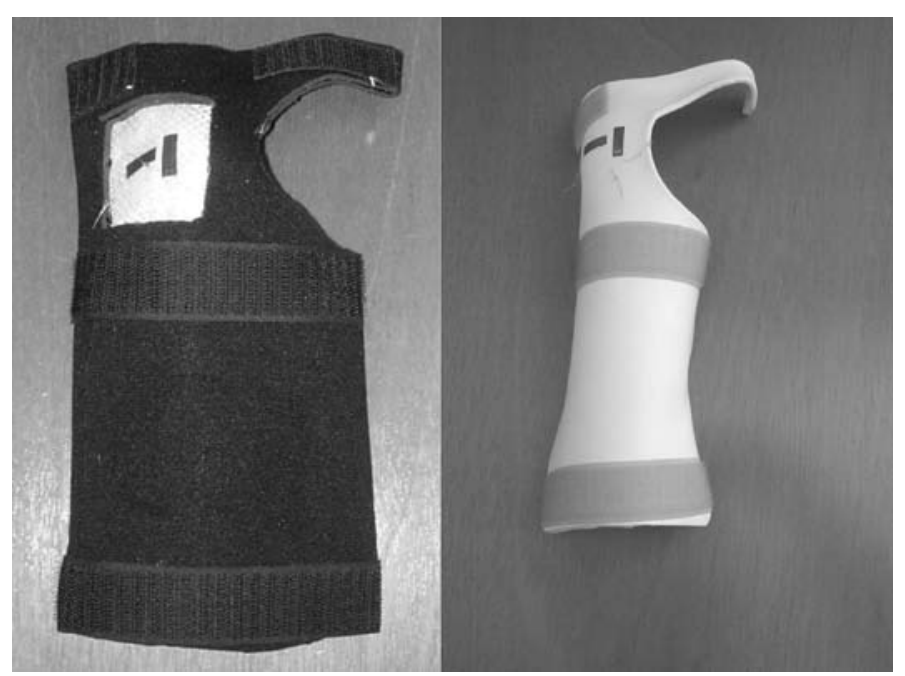

Figura 1 - Órtese de imobilização do punho em extensão - A) material compósito, B) material termomoldável

As órteses foram confeccionadas com o punho posicionado em um ângulo de $15^{\circ}$ de extensão, de forma que todas as demais articulações do membro superior permanecessem livres. Essa escolha teve como base os estudos de Callinan $^{(6)}$, Bulthaup et $a l^{(8)}$ e Stern et $a l^{(23)}$, que preconizaram a utilização de tal ângulo para se avaliar a eficácia, no longo prazo, do uso da órtese de punho em pacientes com diversas desordens do sistema neuromusculoesquelético. Além disso, como mencionam Jansen et $a l^{(7)}$, o ângulo de $15^{\circ}$ é ideal para que os pacientes, quando em uso de órtese, sejam capazes de manter suas atividades diárias, tanto de trabalho e quanto de lazer.

Os dispositivos foram confeccionados na posição prescrita, tomando-se todo o cuidado para que as pregas palmar média, palmar distal e tenar ficassem livres, a fim de não impedir os movimentos do polegar e dos demais dedos durante a realização dos testes. Como proposto por Jansen et $a l^{(7)}$, o comprimento da órtese considerado foi o correspondente ao dobro, em centímetros, da distância da prega palmar distal até a prega proximal do punho, medida em direção ao antebraço. Manteve-se a órtese fixada ao segmento corporal por meio de faixas de velcro posicionadas no dorso da mão, no punho e no terço proximal do antebraço.

Os voluntários foram convidados a participar de nova sessão, em que foram submetidos à avaliação da medida da ativação da musculatura flexora e extensora do punho. O nível de ativação dos dois grupos musculares - o flexor e o extensor - do punho foi monitorado por meio de um eletromiógrafo MP100WSW (Biopac Systems, Inc. Goleta, EUA), cuja capacidade para detectar frequências de coleta é de até $1.000 \mathrm{~Hz}$, com impedância de entrada de $1 \mathrm{G} \Omega$, filtro high-pass para eliminação dos ru- ídos de $10 \mathrm{~Hz}$, filtro low-pass de $500 \mathrm{~Hz}$ e capacidade de rejeição do modo comum de $2 \mathrm{M} \Omega$. Eletrodos ativos de superfície - Ag/AgCl -, com diâmetro de 11,4mm, foram usados para capturar os dados eletromiográficos dos músculos flexores e extensores do punho. Um eletrodo de referência (terra), do mesmo fabricante do eletromiógrafo, foi fixado ao acrômio do lado não dominante, a fim de evitar desconfortos aos participantes e possíveis queixas de dor durante a execução dos movimentos.

Inicialmente, os participantes foram orientados a retirar qualquer vestimenta que pudesse dificultar a colocação dos eletrodos e a sentar-se em uma cadeira para o preparo da pele e a localização da região de maior captação da contração muscular, segundo os procedimentos descritos por Cram et $a^{(24)}$. Isso feito, foi-lhes solicitado contrair os grupos musculares a serem analisados, mediante movimentos de flexão e de extensão do punho, e, por meio de palpação, definiu-se, em cada um dos voluntários, o ponto de maior volume muscular ${ }^{(24,25)}$. Essa forma de monitoramento foi selecionada porque, de acordo com Cram et $a^{(24)}$, a colocação do tipo geral dos eletrodos, avalia o nível geral da tensão muscular em um determinado grupo muscular e é muito usado clinicamente para estudar a tensão geral do segmento corporal, em especial, dos grupos musculares localizados no antebraço, para avaliar o tratamento de dores relacionadas com essa região, tais como lesões por esforços repetitivos.

Para garantir a validade e a precisão dos sinais eletromiográficos, antes da colocação dos eletrodos, fez-se, previamente, uma tricotomia local, usando-se material descartável, a que se seguiu uma limpeza da superfície cutânea, por fricção da pele com gaze estéril embebida com álcool $^{(24)}$. Do mesmo modo, os eletrodos foram limpos com gaze estéril e álcool, antes de ser afixados à pele.

Após devidamente preparados, os eletrodos de detecção foram posicionados sobre a musculatura desejada, identificada anteriormente, mediante palpação do ventre muscular e acompanhando a orientação das fibras musculares $^{(24,26)}$. Para o grupo muscular flexor, os eletrodos foram posicionados na região ventral do antebraço e, para o grupo muscular extensor, na região dorsal do antebraço - em ambos os casos, aproximadamente, a $3 \mathrm{~cm}$ abaixo da cabeça do rádio ${ }^{(7)}$.

Em seguida, todos os eletrodos foram fixados à pele com fita adesiva dupla face e esparadrapo hipoalergênico, para sua melhor aderência, a fim de facilitar a captação adequada dos sinais eletromiográficos. Após a colocação e fixação dos eletrodos, utilizou-se a contração muscular resistida, manualmente, da extensão e da flexão do punho, para verificar a ausência de interferência nos sinais 
correspondentes e a qualidade deles para todos os grupos musculares a serem analisados. Em seguida, a fixação dos eletrodos foi reforçada, em toda a sua extensão, com uma segunda camada de esparadrapo. Para garantir a consistência dos procedimentos, os mesmos eletrodos eram utilizados em cada um dos grupos musculares estudados e, também, sistematicamente colocados pelo mesmo avaliador. As especificações concernentes à coleta dos dados eletromiográficos foram determinadas segundo os procedimentos descritos por Teixeira da Fonseca et al ${ }^{(27)}$.

Para a comparação dos dados eletromiográficos (EMG) intra e intersujeitos, fez-se a normalização dos dados utilizando-se a porcentagem da contração isométrica voluntária máxima (CIVM) do grupo muscular de interesse ${ }^{(28)}$. Os dados eletromiográficos de cada grupo muscular analisado, referenciados em CIVM, foram coletados com o indivíduo posicionado e estabilizado. O protocolo para o referenciamento em CIVM foi explicado a todos os participantes e, não havendo dúvidas a esse respeito, a CIVM de cada um dos grupos musculares investigados foi realizada por seis segundos, sob comando de estímulos verbais do avaliador, para que a contração fosse a mais intensa possível. Para cada movimento, executou-se o mesmo procedimento três vezes, com intervalos de um minuto ${ }^{(24,27)}$.

Os valores da EMG em root mean square (RMS) foram normalizados pela maior root mean square (RMS) observada, durante a realização do teste da CIVM, em cada grupo muscular ${ }^{(29,30)}$. O processamento dos dados eletromiográficos foi realizado utilizando-se o software Acqknowledge e rotinas computacionais desenvolvidas no programa MatLab exclusivamente para atender aos objetivos do presente estudo.

A avaliação da atividade da musculatura flexora e extensora do punho foi iniciada com os participantes submetendo-se ao Teste de Força de Preensão e ao Teste Funcional da Mão de Jebsen-Taylor (J-T), nessa ordem, em três situações: sem o uso da órtese (SO), com o uso de órteses de compósito sanduíche e com uso de órtese de Ezeform ${ }^{\circledR}$. A definição da sequência de teste - isto é, sem ou com uso da órtese - foi definida por sorteio. Nas duas situações, a atividade muscular foi monitorada durante 30 segundos, tempo considerado suficiente para a realização de cada um dos testes.

O Teste Funcional da Mão de Jebsen-Taylor (J-T) é padronizado ${ }^{(31,32)}$ e compõe-se de sete subtestes funcionalmente orientados, a saber: (1) escrever, (2) virar cartas, (3) pegar objetos pequenos, (4) alimentar-se, (5) empilhar blocos, (6) pegar objetos grandes e leves e (7) pegar objetos grandes e pesados. Segundo Jebsen et al ${ }^{(33)}$ e Stern et $a^{(34)}$, esses subtestes são utilizados para esti- mular atividades funcionais, manuais e unilaterais. Foi escolhido por permitir obter uma medida objetiva de tarefas padronizadas e avaliar a função da mão comumente usada em atividades de vida diárias (AVDs) ${ }^{(10,33,34)}$.

Durante a realização do J-T, cada participante permaneceu sentado em uma cadeira de, aproximadamente, $46 \mathrm{~cm}$ de altura, de frente para uma mesa, de $80 \mathrm{~cm}$ de altura, em uma sala bem iluminada. Os sete subtestes foram propostos aos participantes sempre na mesma sequência ${ }^{(33)}$ e realizados apenas com a mão dominante.

Para assegurar a acurácia do teste e consistência dos procedimentos dos participantes, antes de cada sessão, instruções gerais foram dadas pelo avaliador, a fim de se dirimirem quaisquer dúvidas. O voluntário recebeu as orientações de, ao comando do avaliador, dar início ao teste imediatamente e de realizar a tarefa tão rapidamente quanto possível, buscando executá-la, o mais próximo possível, do modo como desempenha o mesmo tipo de atividade no dia a dia. Em caso de erro - deixar cair uma peça, distrairse, confundir-se e outros -, promovia-se a devida correção e o procedimento era imediatamente repetido ${ }^{(10)}$.

O dinamômetro Jamar® foi empregado para medir a força de preensão manual. Para tal, o indivíduo permaneceu sentado confortavelmente, mantendo o ombro aduzido, o cotovelo fletido em $90^{\circ}$ e o antebraço e o punho em posição neutra. Todos os participantes foram instruídos a, sem movimentos rápidos e bruscos, aplicar a força de forma suave. No presente estudo, considerouse como aceitável a extensão do punho até, no máximo, $30^{\circ}$ durante a execução da força máxima, como preconizado pela $\mathrm{ASHT}^{(35)}$ e pela $\mathrm{SBTM}^{(36)}$. Em atendimento à recomendação da $\mathrm{ASHT}^{(35)}$, considerou-se a segunda posição de pega do dinamômetro.

\section{Análise estatística}

Realizou-se a análise inferencial com base na medida do percentual de ativação das musculaturas flexora e extensora do punho durante a realização dos testes sem e com as órteses de compósito e de Ezeform ${ }^{\circledR}$. Os resultados obtidos sem uso de órtese foram comparados com os obtidos com uso da órtese de compósito e da órtese de Ezeform ${ }^{\circledR}$, cujos resultados também foram comparados entre si. Todas as observações feitas tiveram sua significância avaliada estatisticamente. O teste de ShapiroWilk foi utilizado para verificar a distribuição normal dos dados e o teste de postos sinalizados de Wilcoxon, para avaliar a significância dos dados obtidos na comparação dos grupos. Em todas as análises empregou-se o software estatístico SPSS for Windows, versão 13.0, 2004, e considerou-se nível de significância $\alpha=0,05$. 


\section{RESULTADOS}

As Tabelas 1 e 2 apresentam os resultados estatísticos da análise inferencial concernente à quantidade de ativação dos músculos flexores e extensores do punho, respectivamente, normalizada pela CIVM, durante a realização dos testes.

As médias de todas as variáveis relativas à quantidade de ativação dos músculos flexores do punho quando em uso da órtese experimental e de Ezeform ${ }^{\circledR}$ foram superiores a $40 \%$ dos valores utilizados na normalização

Tabela 1 - Valores médios ( \pm desvio-padrão) da quantidade de ativação dos músculos flexores do punho avaliada para cada variável de análise

\begin{tabular}{c|c|c|c|c}
\hline \multicolumn{5}{c}{ Ativação dos músculos flexores } \\
\hline Subteste & $\mathbf{n}$ & $\begin{array}{c}\text { Sem uso de } \\
\text { órtese }\end{array}$ & $\begin{array}{c}\text { Com uso de } \\
\text { órtese de } \\
\text { compósito }\end{array}$ & $\begin{array}{c}\text { Com uso } \\
\text { de órtese } \\
\text { termomoldável }\end{array}$ \\
\hline Alimentar-se & 26 & $0,084 \pm 0,044^{\mathrm{a}, \mathrm{b}}$ & $0,433 \pm 0,171^{\mathrm{a}}$ & $0,423 \pm 0,164^{\mathrm{b}}$ \\
\hline Empilhar blocos & 26 & $0,088 \pm 0,053^{\mathrm{a}, \mathrm{b}}$ & $0,521 \pm 0,194^{\mathrm{a}}$ & $0,513 \pm 0,190^{\mathrm{b}}$ \\
\hline Virar cartas & 26 & $0,190 \pm 0,117^{\mathrm{a}, \mathrm{b}}$ & $0,486 \pm 0,200^{\mathrm{a}}$ & $0,480 \pm 0,190^{\mathrm{b}}$ \\
\hline Escrever & 26 & $0,164 \pm 0,089^{\mathrm{a}, \mathrm{b}}$ & $0,407 \pm 0,159^{\mathrm{a}}$ & $0,398 \pm 0,153^{\mathrm{b}}$ \\
\hline Pegar objetos pequenos & 26 & $0,142 \pm 0,087^{\mathrm{a}, \mathrm{b}}$ & $0,479 \pm 0,184^{\mathrm{a}, \mathrm{c}}$ & $0,459 \pm 0,175^{\mathrm{b}, \mathrm{c}}$ \\
\hline Pegar objetos leves & 26 & $0,141 \pm 0,104^{\mathrm{a}, \mathrm{b}}$ & $0,544 \pm 0,211^{\mathrm{a}, \mathrm{c}}$ & $0,516 \pm 0,191^{\mathrm{b}, \mathrm{c}}$ \\
\hline Pegar objetos pesados & 26 & $0,161 \pm 0,104^{\mathrm{a}, \mathrm{b}}$ & $0,540 \pm 0,208^{\mathrm{a}, \mathrm{c}}$ & $0,521 \pm 0,198^{\mathrm{b}, \mathrm{c}}$ \\
\hline Força de preensão & 26 & $0,356 \pm 0,135^{\mathrm{a}, \mathrm{b}}$ & $0,738 \pm 0,260^{\mathrm{a}, \mathrm{c}}$ & $0,693 \pm 0,25 \mathrm{~g}^{\mathrm{b}, \mathrm{c}}$ \\
\hline
\end{tabular}

Nota: Mesmas letras indicam diferença significativa $(p<0,05)$ entre as respectivas condições experimentais

Tabela 2 - Valores médios ( \pm desvio-padrão) da quantidade de ativação dos músculos extensores do punho avaliada para cada variável de análise

\begin{tabular}{c|c|c|c|c}
\hline \multicolumn{5}{c}{ Ativação dos músculos extensores } \\
\hline Subteste & $\mathbf{n}$ & $\begin{array}{c}\text { Sem uso de } \\
\text { órtese }\end{array}$ & $\begin{array}{c}\text { Com uso de } \\
\text { órtese de } \\
\text { compósito }\end{array}$ & $\begin{array}{c}\text { Com uso } \\
\text { de órtese } \\
\text { termomoldável }\end{array}$ \\
\hline Alimentar-se & 26 & $0,159 \pm 0,068^{\mathrm{a}, \mathrm{b}}$ & $0,141 \pm 0,068^{\mathrm{a}}$ & $0,143 \pm 0,089^{\mathrm{b}}$ \\
\hline Empilhar blocos & 26 & $0,165 \pm 0,071^{\mathrm{a}, \mathrm{b}}$ & $0,138 \pm 0,070^{\mathrm{a}}$ & $0,131 \pm 0,059^{\mathrm{b}}$ \\
\hline Virar cartas & 26 & $0,215 \pm 0,093^{\mathrm{a}, \mathrm{b}}$ & $0,168 \pm 0,080^{\mathrm{a}}$ & $0,164 \pm 0,074^{\mathrm{b}}$ \\
\hline Escrever & 26 & $0,211 \pm 0,092^{\mathrm{a}, \mathrm{b}}$ & $0,184 \pm 0,110^{\mathrm{a}}$ & $0,190 \pm 0,116^{\mathrm{b}}$ \\
\hline Pegar objetos pequenos & 26 & $0,207 \pm 0,096^{\mathrm{a}, \mathrm{b}}$ & $0,152 \pm 0,077^{\mathrm{a}}$ & $0,146 \pm 0,071^{\mathrm{b}}$ \\
\hline Pegar objetos leves & 26 & $0,202 \pm 0,089^{\mathrm{a}, \mathrm{b}}$ & $0,135 \pm 0,063^{\mathrm{a}}$ & $0,132 \pm 0,063^{\mathrm{b}}$ \\
\hline Pegar objetos pesados & 26 & $0,284 \pm 0,115^{\mathrm{a}, \mathrm{b}}$ & $0,192 \pm 0,070^{\mathrm{a}, \mathrm{c}}$ & $0,176 \pm 0,068^{\mathrm{b}, \mathrm{c}}$ \\
\hline Força de preensão & 26 & $0,731 \pm 0,265^{\mathrm{a}, \mathrm{b}}$ & $0,602 \pm 0,178^{\mathrm{a}, \mathrm{c}}$ & $0,534 \pm 0,179^{\mathrm{b}, \mathrm{c}}$ \\
\hline
\end{tabular}

Nota: Mesmas letras indicam diferença significativa $(p<0,05)$ entre as respectivas condições experimentais em CIVM. A ativação da musculatura flexora do punho aumentou até cinco vezes quando comparada sem o uso de órtese e com o uso das órteses.

Com relação à quantidade de ativação dos músculos extensores, as médias de todas as variáveis quando em uso da órtese experimental foram inferiores a $20 \%$ dos valores utilizados na normalização em CIVM, exceto no que diz respeito à ativação quando se testa o uso da força de preensão, que foi igual a $60 \%$. A redução da ativação da musculatura extensora variou entre $10 \%$ para as atividades de alimentação e escrita e 38\% para as atividades de pegar objetos pesados.

Foram encontradas diferenças estatisticamente significativas entre os resultados do J-T e Teste da Força de Preensão obtidos sem o uso de órtese e com o uso da órtese (experimental ou de Ezeform ${ }^{\circledR}$ ) para a ação tanto dos músculos flexores quanto dos extensores (valor $\mathrm{p}<0,05$ ).

Ao se compararem os resultados da ativação com o uso das diferentes órteses, nota-se que o aumento na ativação dos flexores com o uso da órtese experimental foi ligeiramente superior àquele obtido com o uso da órtese de Ezeform ${ }^{\circledR}$, porém, essa diferença não foi considerada significativa, exceto para os subtestes de pegar objetos leves $(p=0,029)$, pegar objetos pesados $(p=0,01)$ e para o teste de força de preensão $(p=0,015)$. Por sua vez, para o grupo muscular extensor do punho, observou-se que a redução na ação dos extensores com o uso da órtese de Ezeform ${ }^{\circledR}$ foi ligeiramente maior do que com a órtese experimental, porém, essa diferença não foi considerada significativa, exceto para os subtestes pegar objetos pesados e força de preensão $(p=0,011)$.

\section{DISCUSSÃO}

Vários estudos têm buscado avaliar se o uso de órteses de punho pode gerar a estabilização passiva do punho reduzindo a carga extensora dos músculos do punho, resultado importante para a definição da indicação ou não do uso de órteses no processo de reabilitação de várias desordens musculoesqueléticas ${ }^{(13)}$. Isto é, verificar se é possível obter, com o uso de uma simples órtese, a prevenção de flexão do punho, redução de processos inflamatórios dos extensores de punho, entre outras condições de estresse da musculatura.

Os resultados obtidos neste estudo diferem parcialmente dos encontrados na literatura que, em geral, relatam que o uso de órtese não altera ${ }^{(37)}$ ou aumenta a ação dos músculos extensores do antebraço ${ }^{(8,13)}$. Apenas Jansen et $a l^{(7)}$ e Roy et $a l^{(38)}$ observaram redução da atividade dos extensores. 
Este estudo apontou que o uso de órtese interferiu na ativação elétrica dos músculos flexores e extensores do punho. Observou-se que o uso de órtese de imobilização do punho em extensão (150), qualquer das testadas, gerou a diminuição da ação dos extensores e o aumento da ação dos flexores do punho durante a execução dos testes de força de preensão e de função manual.

Com relação à musculatura extensora, este estudo indicou que o uso das órteses testadas reduziu a carga extensora durante a realização das tarefas. Nota-se que, durante a realização dos testes, tanto a órtese de compósito quanto a órtese de Ezeform ${ }^{\circledR}$ recrutaram significativamente menos atividade muscular dos extensores do punho do que com a mão livre.

Os achados deste estudo indicam que a órtese substitui a ação primária dos músculos extensores do punho (extensão da articulação) e mantém a musculatura encurtada, diminuindo assim a atividade desse grupo muscular. Segundo Jansen et $a l^{(7)}$, a órtese de extensão de punho limita o alongamento passivo dos extensores diminuindo, consequentemente, a atividade muscular durante as atividades funcionais. Sabe-se que os extensores do punho têm como função proporcionar estabilidade contra a força dos flexores dos dedos para prevenir a flexão do punho, que ocorre simultaneamente à flexão dos dedos durante a preensão ${ }^{(10,13,39)}$. Para manter essa estabilidade durante a preensão, a coativação e ativação individual dos flexores e extensores do punho são fundamentais ${ }^{(11)}$. Além disso, os extensores extrínsecos dos dedos, por insuficiência passiva, e os flexores extrínsecos, por insuficiência ativa, têm ação contensora e impedem a flexão simultânea das articulações do punho e dedos ${ }^{(40)}$. Esse mecanismo sugere que os extensores do punho têm o duplo papel de inibir e estabilizar forças durante o movimento de preensão ${ }^{(12,13)}$.

Ainda com relação à atividade da musculatura extensora, observou-se que a redução da ativação dessa musculatura, proporcionalmente, foi menor nas atividades de alimentar-se e escrever do que aquela observada em outros testes. Essa reação pode estar relacionada com o pequeno arco de movimento do punho necessário durante a realização dessas atividades. Nessas tarefas, a musculatura extensora do punho trabalha, essencialmente, mantendo essa articulação em determinada posição para permitir a função dos dedos.

Por outro lado, observou-se maior redução da ativação da musculatura extensora do punho durante a realização das atividades que exigiam maior grau de força de preensão ou maior arco de movimento do punho e dedos. Esse dado pode indicar que o uso de órtese de imobilização do punho pode ser mais eficaz nesses casos. Sabe-se, por exemplo, que a epicondilite pode ter seus sintomas agravados quando do uso extremo da mão e antebraço, bem como com o aumento da exigência de carga física $^{(41)}$. Aparentemente, o uso da órtese pode ter bom resultado para indivíduos que apresentem tais características de trabalho.

Com relação ao aumento da atividade dos músculos flexores durante a realização das tarefas com o uso de órtese, este estudo parece corroborar o descrito por Bulthaup et $a l^{(8)}$, que consideram que as órteses de imobilização do punho em extensão são desenhadas para limitar o movimento da articulação e, nesse caso, para a realização da preensão, os flexores do punho necessitarão ter sua ação aumentada, tendo em vista o esforço necessário para vencer a restrição imposta pela órtese. Em seu estudo, Bulthaup et $a l^{(8)}$ sugerem ainda que uma órtese mais restritiva exija maior tensão dos músculos contra a órtese para possibilitar o movimento mais próximo do padrão normal. Sobre esse aspecto, neste estudo pode-se considerar a órtese de Ezeform ${ }^{\circledR}$ como mais restritiva, tendo em vista sua rigidez (superior à do compósito), o que implicaria maior ativação dos flexores com o seu uso. No entanto, este estudo, embora não conclusivo, indica o contrário. Observou-se maior exigência da ativação dos flexores, embora não significativa, quando se comparou o uso da órtese de Ezeform ${ }^{\circledR}$ com a órtese de compósito. Ao que parece, o uso de diferentes materiais para confecção de órtese não interfere na ação da musculatura extensora ou flexora do punho. Isso sugere que a indicação do material para confecção do dispositivo ortótico deve levar em conta o maior conforto e melhor adaptação do indivíduo.

Outra questão a ser considerada está relacionada com o grau de extensão de punho utilizado para confecção das órteses. Os resultados deste estudo dizem respeito ao ângulo de 15 graus de extensão e angulações distintas dessa podem gerar diferentes resultados. Sabe-se que cada indivíduo desempenha suas tarefas diárias à sua maneira, com exigências diferentes quanto aos graus de movimento da articulação do punho, o que poderia indicar outra angulação do punho para confecção da órtese.

O presente estudo observou que o uso da órtese interfere significativamente na ação dos músculos flexores e extensores do punho. O uso da órtese reduz a ativação dos músculos extensores do punho durante a realização de tarefas específicas, mas também aumenta a ativação dos músculos flexores. Os achados indicam que o uso de órtese de imobilização do punho em extensão proporciona 
estabilização passiva do punho, reduzindo a carga extensora dos músculos do punho. Por outro lado, esse mesmo uso gera aumento da atividade dos músculos flexores do punho, o que indica que o dispositivo restringe o movimento e que essa musculatura necessita ser ativada em maior grau para vencer tal restrição. Esse é um resultado importante para a definição da indicação, ou não, do uso de órteses no processo de reabilitação de várias desordens - entre outras, a tendinite de flexores e extensores do punho e dos dedos, bem como para a previsão do tempo de uso desses dispositivos. Em especial, este estudo chama a atenção para a maior efetividade da órtese de extensão de punho na redução da musculatura extensora do punho durante a execução de tarefas que exigem maior grau de força muscular (pegar objetos pesados e teste de força muscular); ao posicionamento do punho (150); e quanto à indicação de diferentes materiais para confecção da órtese que devem ser mais bem avaliados.

As divergências observadas entre os estudos pesquisados e este estudo podem ser justificadas pelas diferenças metodológicas entre eles, tais como, o tipo de tarefa realizada, o tipo de órtese utilizado, o tipo de sujeito estudado. Essas diferenças apontam para a necessidade de novos estudos na área, para a busca de evidência científica sobre a real adequação do uso da órtese ou não na reabilitação de tais desordens.

\section{AGRADECIMENTOS}

Ao Conselho Nacional de Desenvolvimento Científico e Tecnológico (CNPq), Processos $n^{0}$ 550256/2007-5 e 471585/2004-1.

\section{REFERÊNCIAS}

1. Cook A, Hussey S. Assistive technology: principles and practice. St. Louis: Mosby; 1995.

2. Hammel J, Lai Jin-Shei, Heller T. The impact of assistive technology and environmental interventions on function and living situation status with people who are ageing with developmental disabilities. Disabil Rehabil. 2002;24(1-3):93-105.

3. Trombly CA. Terapia ocupacional para disfunções físicas. 5a ed. São Paulo: Santos Livraria Editora; 2005.

4. Fess EE. A history of splinting: to understand the present, view the past. J Hand Ther. 2002;15(2):97-132.

5. Fess EE. Splints: mechanics versus convention. J Hand Ther. 1995;8(2):124-30.

6. Callinan N. Clinical interpretation of "an electromyography study of wrist extension orthoses and upper-extremity function". Am J Occup Ther. 1999;53(5):441-4.

7. Jansen CWS, Olson SL, Hasson SM. The effect of use of a wrist orthosis during functional activities on surface electromyography of the wrist extensors in normal subjects.. J Hand Ther. 1997;10(4):283-9.

8. Bulthaup S, Cipriani DJ 3rd, Thomas JJ. An electromyography study of wrist extension orthoses and upper-extremity function. Am J Occup Ther. 1999;53(5):434-40.

9. Schultz-Johnson K. Splinting the wrist: mobilization and protection. J Hand Ther. 1996;9(2):165-77.

10. Carlson JD, Trombly CA. The effect of wrist immobilization on performance of Jebsen hand function test. Am J Occup Ther. 1983;37(3):167-75.

11. Matsushita N, Handa Y, Ichie M, Hoshimiya N. Electromyogram analysis and electrical stimulation control of paralysed wrist and hand. J Electromyogr Kinesiol. 1995;5(2):117-28.

12. Bober T, Kornecki S, Lehr RP Jr, Zawadzki J. Biomechanical analysis of human arm stabilization during force production. J Biomech. 1982;15(11):825-30.

13. Johansson L, Björing G, Hägg GM. The effect of wrist orthoses on forearm muscle activity. Appl Ergon. 2004;35(2):129-36.

14. Cohen J. Statistical power analysis for the behavioral sciencies. 2nd ed. New Jersey: Lawrencw Erlbaum Associates Publishers; 1988.

15. Rodrigues AMVN. Desenvolvimento de compósito sanduíche para confecção de órteses e o efeito da órtese de compósito na função manual e na ativação dos músculos do antebraço [tese]. Belo Horizonte: Universidade Federal de Minas Gerais, Escola de Engenharia; 2007.

16. Lee DB. Objective and subjective observations of low-temperature thermoplastic materials. J Hand Ther. 1995;8(2):138-43.

17. Carmick J. Use of neuromuscular electrical stimulation and [corrected] dorsal wrist splint to improve the hand function of a child with spastic hemiparesis. Phys Ther. 1997;77(6):661-71.

18. Courts RB. Splinting for symptoms of carpal tunnel syndrome during pregnancy. J Hand Ther. 1995;8(1):31-4.

19. Feuerstein M, Burrell LM, Miller VI, Lincoln A, Huang GD, Berger R. Clinical management of carpal tunnel syndrome: a 12-year review of outcomes. Am J Ind Med. 1999;35(3):232-45.

20. Krajnik SR, Bridle MJ. Hand splinting in quadriplegia: current practice. Am J Occup Ther. 1992;46(2):149-55.

21. Pardini Junior A, Souza JMG. Clínica ortopédica - o cotovelo. Belo Horizonte: Editora Médica e Científica; 2002.
22. Struijs PA, Kerkhoffs GM, Assendelft WJ, Van Dijk CN. Conservative treatment of lateral epicondylitis: brace versus physical therapy or a combination of both-a randomized clinical trial. Am J Sports Med. 2004;32(2):462-9.

23. Stern EB. Grip strength and finger dexterity across five styles of commercial wrist orthoses. Am J Occup Ther. 1996;50(1):32-8.

24. Cram JR, Kasman GS, Holtz J. Introduction to surface electromyography. Maryland: Aspen Publishers; 1998.

25. Soderberg GL, Knutson LM. A guide for use and interpretation of kinesiologic electromyographic data. Phys Ther. 2000;80(5):485-98.

26. Hägg GM, Milerad E. Forearm extensor and flexor muscle exertion during simulated gripping work: an electromyographyc study. Clin Biomech. 1997;12(1):39-43.

27. Teixeira da Fonseca S, Silva PL, Ocarino JM, Guimarães RB, Oliveira MT, Lage CA. Analyses of dynamic co-contraction level in individuals with anterior cruciate ligament injury. J Electromyogr Kinesiol. 2004;14(2):239-47.

28. Basmajian JV, Deluca CJ. Muscle alive. Their function revealed by electromyography. Baltimore: Williams \& Wilkins; 1985.

29. Knutson LM, Soderberg GL, Ballantyne BT, Clarke WR. A study of various normalization procedures for within day electromyography data. J Eletromyogr Kinesiol. 1994;4(1):47-59

30. Hillstrom HJ, Triolo RJ. EMG theory. In: Craick RL, Oatis CA, editors. St. Louis: Mosby; 1995. p.271-92.

31. Stern EB. Stability of the Jebsen-Taylor Hand Function Test across three test sessions. Am J Occup Ther. 1992;46(7):647-9.

32. Hackel ME, Wolfe GA, Bang SM, Canfield JS. Changes in hand function in the aging adult as determined by the Jebsen Test of Hand Function. Phys Ther. 1992;72(5):373-77.

33. Jebsen RH, Taylor N, Trieschmann RB, Trotter MJ, Howard LA. An objective and standardized test of hand function. Arch Phys Med Rehabil. 1969;50(6):311-9.

34. Stern EB, Sines B, Teague TR. Commercial wrist extensor orthoses. J Hand Ther. 1994;7(4):237-44.

35. American Society of Hand Therapists. Clinical assessment recommendations. Chicago: ASHT; 1992.

36. Sociedade Brasileira de Terapia da Mão. Recomendações para avaliação do membro superior. Joinville: Sociedade Brasileira de Terapia da Mão; 2005.

37. Burtner PA, Anderson JB, Marcum ML, Poole JL, Qualls C, Picchiarini MS. A comparison of static and dynamic wrist splints using electromyography in individuals with rheumatoid arthritis. J Hand Ther. 2003;16(4):320-5.

38. Roy SH, O'Hara JM, Briganti M. Use of EMG spectral parameters to evaluate fatigue associated with pressure glove work. In: Eletromyographical kinesiology, Elsevier Science, Exerpta Medica, International Congress Series 9/9, Amsterdam; 1991. p. 283-6.

39. Snijders CJ, Volkers AC, Mechelse K, Vleeming A. Provocation of epicondylalgia lateralis (tennis elbow) by power grip or pinching. Med Sci Sports Exerc. 1987;19(5):518-23.

40. Lehmkuhl L, Smith L. Cinesiologia clínica. 4a ed. São Paulo: Manole; 1987.

41. Haahr JP, Andersen JH. Prognostic factors in lateral epicondylitis: a randomized trial with one-year follow-up in 266 new cases treated with minimal occupational intervention or the usual approach in general practice. Rheumatology. 2003;42(10):1216-25. 